\title{
Aspectos morfológicos, morfométricos e topográficos do aparelho digestório de Chinchilla lanigera
}

\author{
Tiane Ferreira de CASTRO ${ }^{1}$ \\ Rodrigo Jeske DUMMER ${ }^{1}$ \\ Eduardo Madruga RICKES ${ }^{2}$ \\ Malcon Andrei Martinez \\ PEREIRA $^{3}$
}

Correspondência para:

Malcon Andrei Martinez Pereira, Laboratório Neurobiologia Comparada, Departamento Fisiologia, ICBS UFRGS, Rua Sarmento Leite, 500, Porto Alegre, RS, Brazil, CEP: 90046-900, (51) 33083305

malconantato@yahoo.com.br

Recebido para publicação: 22/11/2005 Aprovado para publicação: 23/04/2007

\author{
1- Acadêmico de Medicina Veterinária, Universidade Federal de Pelotas, \\ Pelotas-RS \\ 2- Médico Veterinário \\ 3- Programa de Pós-graduação Neurociências, Laboratório Neurobiologia \\ Comparada, Departamento Fisiologia, Instituto Ciências Básicas da Saúde, \\ Universidade Federal Rio Grande do Sul, Porto Alegre-RS
}

\section{Resumo}

O objetivo deste estudo foi o de descrever os aspectos morfológicos e topográficos do Aparelho Digestório (AD) de chinchilas, mediante a dissecação de dez animais. Os segmentos do $\mathrm{AD}$ foram coletados e demarcados, seguido de análise volumétrica dos órgáos cavitários, por meio de injeção de solução salina a $60^{\circ} \mathrm{C}$, além da mensuração dos comprimentos dos órgãos tubulares. Nos órgãos parenquimatosos realizou-se a sua pesagem. Durante a análise da disposição dos órgãos, evisceração e medição, observou-se que a cavidade oral é característica de roedores, as glândulas salivares são semelhantes às de lagomorfos e órgãos como esôfago, estômago, duodeno, cólon transverso, fígado, pâncreas e baço apresentam-se dispostos de forma semelhante ao descrito nas outras espécies. Já o jejuno e o cólon descendente foram evidenciados muito extensos e dispostos de forma ondulatória, suspensos no teto da cavidade abdominal. $\mathrm{O}$ íleo assemelhou-se ao descrito para as outras espécies, porém sua disposição topográfica é da direita para esquerda, direcionandose ao ceco, o qual se constitui de duas porçôes distintas e bem desenvolvidas. Ambas as partes encontram-se localizadas à esquerda do plano mediano. O cólon ascendente dispóe-se de forma bastante particular, ocorrendo a presença de uma alça dupla que realiza um looping junto ao fígado. Uma característica relevante foi evidenciada ao comparar-se o reto de machos e fêmeas, o qual apresenta maior comprimento nos machos. De posse dos resultados concluímos que, apesar da chinchila ser um roedor, há características próprias da espécie e também outras que se assemelham aos lagomorfos, constituindo uma relação entre essas ordens.

\section{Introdução}

A espécie Chinchilla lanigera é um animal bastante visado no comércio de peles, estando sua criação em pleno desenvolvimento. Apesar de sua importância comercial, e sua recente inclusão no comércio de animais de estimação, observa-se a existência de poucos estudos relacionados à sua anatomia. Tal fato dificulta o trabalho de
Palavras-chave: Anatomia. Aparelho digestório. Topografia. Morfometria. Chinchilla.
Médicos Veterinários ao prestarem serviços que objetivam a cura de enfermidades e melhoria na qualidade de vida destes animais e, consequentemente, nos produtos vinculados a eles. Atualmente, a maioria dos procedimentos clínicos e cirúrgicos aplicados é realizada de forma empírica, apenas considerando sua anatomia semelhante à de outras espécies, sem relevar suas características particulares. 
Mesmo que estudos realizados descrevam a anatomia de $\operatorname{ratos}^{1,2}$, porcosda-Índia ${ }^{3}$, hamsters ${ }^{4}$ e coelhos ${ }^{5,6}$, ainda há lacunas quanto à comparação às chinchilas, no que diz respeito aos aspectos relacionados ao $\mathrm{AD}$. Para tanto, este estudo destina-se à descrição dos órgãos constituintes do $\mathrm{AD}$, assim como de seus órgãos anexos, visto que distúrbios relacionados a este aparelho influenciam muito a comercialização destes animais.

Tendo em vista a necessidade de solucionar tais problemas e melhorar a produção, aliada ao fato de não haver estudos anteriores voltados a estes pontos, torna-se essencial a realização de um estudo que ressalte aspectos fundamentais na descrição da constituição deste aparelho. Este trabalho visa, ainda, a descrição da topologia e topografia deste aparelho para esta espécie, a fim de avaliar suas respectivas disposiçóes, trajetos, comprimentos, volumetria, assim como relações de sintopia. Com base na pesquisa realizada, torna-se possível propor a construçáo de um modelo anatômico padrão para chinchilas, a partir dos parâmetros morfológicos e topográficos relatados.

\section{Materiais e Métodos}

Para este estudo foram utilizados dez animais da espécie Chinchilla lanigera, provenientes de criatórios comerciais da cidade de Pelotas, RS. O grupo de animais analisados constitui-se de cinco machos e cinco fêmeas. Estes se encontravam no período de abate (8-11 meses), e a eutanásia ocorreu no local de criação. Após a remoção da pele, procedera-se imediatamente a dissecação, com a finalidade de evitar que alteraçóes post-mortem ocasionassem dados imprecisos sobre localização, posição, volumetria e sintopia. De posse dos animais, iniciou-se a dissecação por meio de uma longa incisão que partiu da regiáo do mento até a entrada da cavidade torácica, onde se procedeu a desarticulaçáo das costelas e esterno, na altura das articulaçóes costo-condrais. A incisão seguiu-se sobre a linha alba, terminando ao final da sínfise pélvica, com a desarticulaçáo do osso coxal, e concomitantemente foram rebatidos os músculos adjacentes a estas regióes. Tendo as vísceras totalmente expostas, confeccionouse registro fotográfico e esquemático, visando ilustrar a descrição. Também se realizou este procedimento em cada víscera no momento de sua retirada do interior da cavidade. Terminando esta etapa, foram coletados e compilados os dados relativos à: esqueletopia, topografia, topologia e sintopia, para logo após cada animal ser eviscerado por completo, iniciando-se a partir da língua até o ânus, onde se respeitou o limite das cavidades torácica, abdominal e pélvica. Em cada uma destas cavidades observaram-se os limites de cada órgão e suas regióes de transição, bem como os meios de fixação de cada um. Os órgãos cavitários de maior expressão (estômago e ceco), após terem sido coletados foram injetados com solução salina à $60^{\circ} \mathrm{C}$, para que se pudesse observar sua capacidade volumétrica. As estruturas tubulares tiveram mensurados seus comprimentos, enquanto que as parenquimatosas foram pesadas em balança de precisão.

\section{Resultados e Discussão}

O AD tem seu início na cavidade oral (CO), que se encontra delimitada oralmente pelo lábio maxilar fendido e pelo mandibular único, ambos de bordos finos; lateralmente pelos músculos bucinador, bastante delgado e reduzido, e masseter, muito desenvolvido; seu limite caudal é representado por um palato mole extremamente desenvolvido, que recobre a entrada da orofaringe. Dorsorostralmente na cavidade é possível visualizar uma proeminente papila incisiva que se destaca do palato duro. Durante a análise dos espécimes observou-se um sulco oral ${ }^{7}$. ao redor dos dentes molariformes mandibulares. A língua apresenta o ápice e a base com formato de seta, com um tórus saliente e bem demarcado. 
As chinchilas são heterodontes, possuindo dentes que atuam cortando e coletando o alimento (incisivos em número de quatro, distribuídos aos pares nos ossos incisivos e corpo da mandíbula) e que trituram ou moem (molariformes, com formato cubóide, de superfície plana em um total de oito maxilares e oito mandibulares); totalizando dez maxilares e dez mandibulares. A fórmula dentária varia em relação a outros roedores e o coelho, contudo a distribuição em dentes incisivos e molariformes é descrita no segundo, assim como em capivaras ${ }^{7}$. Em ratos ${ }^{1}$, foi observado a ausência de dentes pré-molares e um total de 16 dentes, divididos entre incisivos e molares maxilares e mandibulares. Em coelhos ${ }^{5,8}$, evidenciaram a presença de quatro dentes incisivos maxilares e dois mandibulares, e cinco molariformes, divergindo dos dados observados em nossa pesquisa. Capivaras (Hydrochaeris hydrochaeris), no entanto, apresentam a mesma constituição dentária encontrada em chinchilas, porém há uma divergência quanto à superfície dos dentes molariformes nesta espécie, que apresentam irregulares com leves projeçôes pontiagudas. Ainda podemos ressaltar que em capivaras o último dente molariforme apresenta tamanho maior que os demais dentes de mesmo tipo ${ }^{7}$, divergindo do observado em chinchilas.

A orofaringe apresenta um formato cubóide, comunica-se com o esôfago pela primeira porção, cervical, que apresenta comprimento médio de $3,1 \mathrm{~cm}$, acompanhando dorsalmente à traqueia, sob o plano mediano (PM). Ao nível do terço médio sofre um ligeiro desvio para esquerda, mantendo esta posição até adentrar a cavidade torácica, onde passa a ser denominado de esôfago torácico, que apresentou comprimento médio de 5,6 $\mathrm{cm}$. Ao nível da nona costela atravessa o músculo diafragma, penetrando na cavidade abdominal (CA), denominando-se esôfago abdominal, com comprimento médio de 1,2 $\mathrm{cm}$. Este se encontra levemente deslocado à esquerda do PM, cursando dorsalmente ao fígado e comunicando-se ao estômago na região do cárdia ao nível do nono espaço intercostal (EIC). Durante seu trajeto, o esôfago não apresenta angulaçóes verticais e totalizou $9,8 \mathrm{~cm}$ de comprimento. A morfologia evidenciada na orofaringe e esôfago foi semelhante à observada em outros roedores, como ratos ${ }^{1}$.

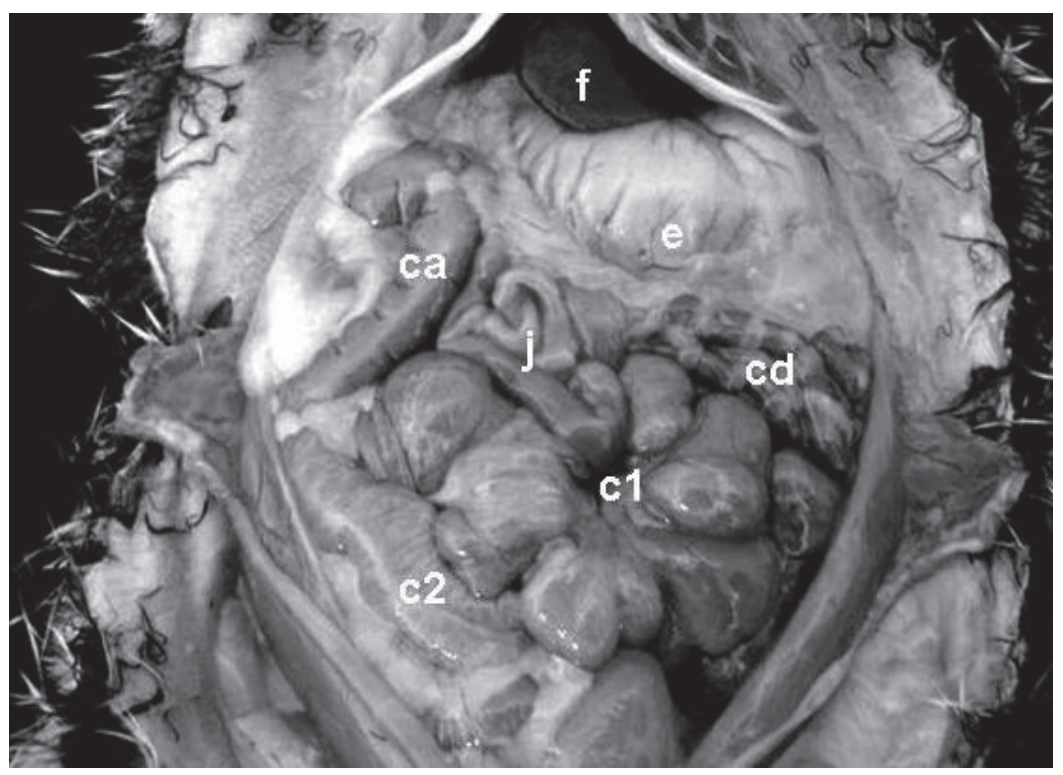

Figura 1- Fotografia evidenciando a disposição in situ dos órgãos da cavidade abdominal, mostrando: fígado (f), estômago (e), jejuno (j), ceco primeira porção (c1) e segunda porção (c2), cólon ascendente (ca) e cólon descendente $(\mathrm{cd})$ 
O estômago apresenta-se monocavitário simples (Figura 1), semelhante ao evidenciado em estudos com ratos' ${ }^{9}$. Localizase nos terços médio e ventral da CA. Quando vazio, está disposto entre a $10^{\mathrm{a}}$ e a $12^{\mathrm{a}}$ costela, e encontrando-se $2 / 3$ à esquerda do PM. Quando cheio está entre o nono EIC e a $\mathrm{L}_{2}$, tocando o teto e o assoalho da CA. Encontrase fixo pelos omentos maior (estendendose desde sua curvatura maior até o cólon transverso e a parede) e menor (fígado) e omento gastro-esplênico (baço). $\mathrm{O}$ piloro encontra-se à direita do PM, comunicando-se com o duodeno. Sua capacidade volumétrica média foi de $89,3 \mathrm{~cm}^{3}$. Deste modo, apesar de não haver dados volumétricos deste órgão para as espécies analisadas, impossibilitando uma comparação concreta, podemos inferir, baseados na topologia descrita, que não foram observadas variaçóes significantes quando comparado aos dados obtidos no estudo realizado por Wang et al. ${ }^{4}$.

A primeira porção do intestino delgado, o duodeno, apresentou $15,9 \mathrm{~cm}$ e seu início ao nível do $11^{\circ}$ EIC (Figuras 1 e 3). A porção cranial apresenta-se pequena (média 2,2 cm) e disposta transversalmente e à direita do PM, dirigindo-se ventrodorsalmente até atingir o teto da CA.
Esta porção do duodeno apresenta um divertículo duodenal, onde desembocam os ductos cístico e pancreático. Este assume um trajeto longitudinal chamado duodeno descendente, que se localiza à direita do PM no terço dorsal da CA, dirigindo-se em trajeto descendente desde a $12^{a}$ costela até próximo da entrada da cavidade pélvica $(\mathrm{CP})$ e possui em média $6,1 \mathrm{~cm}$. Apresenta íntima relação com o pâncreas, estando dorso-lateralmente à direita deste, ambos fixos por uma prega peritoneal, o mesoduodeno. Quando próximo da entrada da CP, assume um trajeto transversal, que lhe confere a denominaçáo de duodeno transverso. Esta porção foi constatada com aproximadamente $2,6 \mathrm{~cm}$, disposta levemente oblíqua junto ao teto da CA no sentido caudo-cranial e dirigindo-se da direita para esquerda, até ficar sob o PM. A partir deste ponto, dispóe-se longitudinalmente no sentido caudocranial, sendo denominado duodeno ascendente. Este se encontra sob o PM e no terço dorsal da CA, desde a entrada da CP até o nível $\mathrm{de}_{2}$, apresentando comprimento médio de $5,1 \mathrm{~cm}$. A disposição e trajeto assumidos pelo duodeno foram semelhantes ao evidenciado para $\operatorname{ratos}^{1}$ e carnívoros ${ }^{10,11}$.

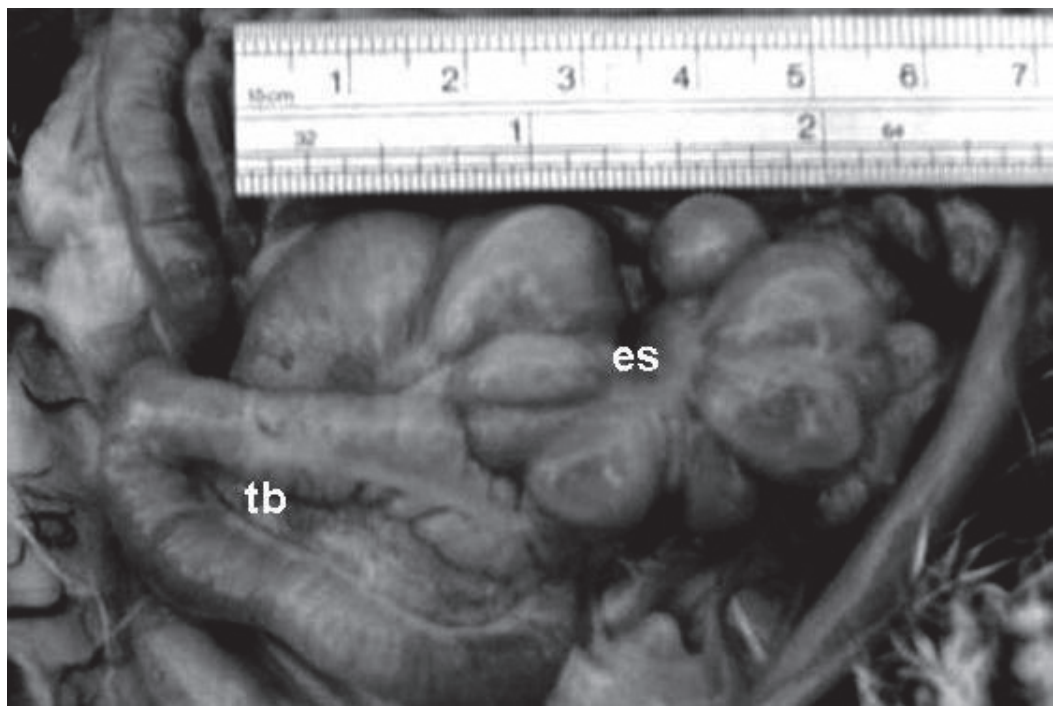

Figura 2- Fotografia evidenciando a morfologia do ceco, sendo a primeira porção espiral-sacular (es) e a segunda tubular (tb) 


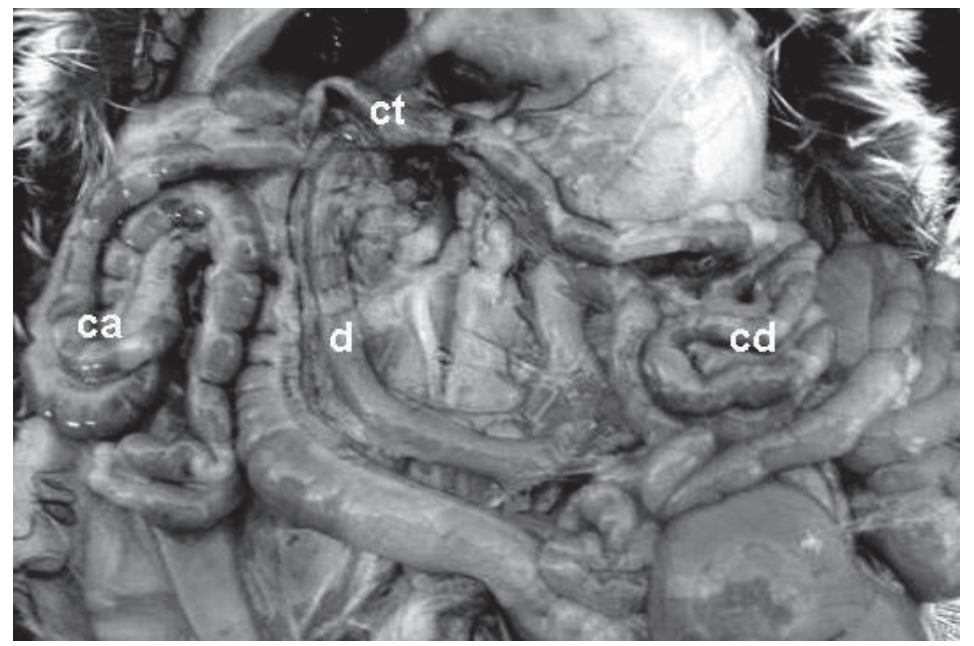

Figura 3- Fotografia mostrando a morfologia e disposição do duodeno (d), cólon ascendente (ca), cólon transverso (ct) e parte do cólon descendente (cd)

O jejuno comunica-se com a extremidade terminal do duodeno ascendente (Figura 1). Este apresenta semelhança externa ao duodeno, sendo um tubo liso e de cor rosado claro. Encontrando-se fixo ao teto da CA pelo mesentério, concentrandose principalmente nos terços dorsal e médio da CA. Encontra-se mais à direita devido ao volume do ceco e pronunciado comprimento do cólon descendente. Possui um comprimento aproximado de 114,6 $\mathrm{cm}$ e dispóe-se de forma ondulatória. Seu comprimento expressivo difere do descrito para carnívoros ${ }^{10}$, que apresentam um intestino delgado relativamente curto, o que facilita a ingesta rápida e em grandes quantidades. Aproximadamente ao nível de $\mathrm{L}_{4.5}$ assume uma disposição retilínea e oblíqua no sentido crânio-caudal, constituindo o íleo, que se dirige da direita para esquerda e apresenta semelhança externa ao jejuno. Entretanto em ratos ${ }^{1}$ e gambás ${ }^{12}$ foi relatado que este apresenta um trajeto caudo-cranial, dirigido, também, da direita para esquerda. Este segmento apresenta em média $4,9 \mathrm{~cm}$ e desemboca na primeira porção do ceco.

$\mathrm{O}$ ceco, primeira parte do intestino grosso, foi observado como um órgão bastante volumoso (Figura 1), assim como o evidenciado para ratos ${ }^{9}$ e Microtus brandti $i^{4}$, devido aos processos fermentativos realizados por estes. Observou-se que este órgão constitui-se de duas porçóes bem distintas, divergindo do descrito para coelhos ${ }^{13}$ para os quais relataram três porçóes. $\mathrm{O}$ formato observado muito se assemelha ao citado por Snipes ${ }^{2}$ para o gerbil, onde a primeira porção apresenta saculaçóes bem dilatadas e um formato espiral e a segunda como uma estrutura tubular levemente pregueada (Figura 2). Encontra-se à esquerda do PM, ocupando o terço ventral e parte do médio. A variação de sua posição condiz ao evidenciado para ratos $^{1}$ e gambás ${ }^{12}$. A primeira porção apresentou volumetria média de 113,1 $\mathrm{cm}^{3}$. Observou-se a presença de uma prega peritoneal entre esta porção e o duodeno transverso, a prega duodeno-cecal. A segunda porção do ceco possui menor calibre do que a primeira e apresenta um leve pregueamento da parede (Figura 2). Dispóe-se de modo em que apresenta uma flexura, voltando sobre ele mesmo. Mesmo disposto em ambos os lados do PM, concentra-se mais à esquerda deste. Encontra-se ao nível de $\mathrm{L}_{5}$ e média de 25,9 $\mathrm{cm}$ de comprimento (Figura 3).

O cólon ascendente, que se comunica com a segunda porção do ceco, apresenta-se como um tubo levemente pregueado, cujo comprimento aproximado é de $60,6 \mathrm{~cm}$ 
(Figuras 1 e 3). Este se dirige cranialmente, sendo representado por uma alça simples. Ao nível do fígado, ele se volta caudalmente até a entrada da CP. Porém, ao nível da $12^{\mathrm{a}}$ costela, realiza um looping. Neste aspecto é possível relatar uma divergência ao descrito por Möller, Pérez e Martin ${ }^{13}$, no seu estudo em coelhos, onde expóe que o cólon ascendente possui três loopings (proximal, intermédio e distal), fato não observado em chinchilas. Estas apresentam um único looping, orientado caudalmente. $\mathrm{Na}$ entrada da CP volta-se cranialmente acompanhando a primeira porção, de trajeto descendente, até o nível de $\mathrm{L}_{1}$ onde origina a porção denominada cólon transverso, localizada no terço médio da CA, dirigindo-se da direita para esquerda e comprimento médio de $5,9 \mathrm{~cm}$. A morfologia evidenciada para esta porção foi semelhante a outras espécies como ratos $^{1}$ e carnívoros ${ }^{10}$.

O cólon descendente tem seu início ao nível de $\mathrm{L}_{2}$, à esquerda do $\mathrm{PM}$, ocupa o terço dorsal e parte do terço médio da $\mathrm{CA}$, onde se encontra fixado no teto da CA por uma prega peritoneal, o mesocólon descendente (Figuras 1 e 3). Concentra-se basicamente à esquerda do $\mathrm{PM}$, dorsalmente às duas porções do ceco. Porém, seu comprimento médio de $109 \mathrm{~cm}$ supera muito o espaço que lhe é conferido, por isso, dispóe-se de forma irregular e ondulatória, semelhante à disposição evidenciada em equinos ${ }^{10,11} \cdot \mathrm{Na}$ sua extremidade aboral, passa a assumir uma disposição retilínea, longitudinal dirigida caudalmente e sob o PM. Neste ponto observou-se sua relaçáo com estruturas do aparelho urogenital, onde se evidenciou que o ureter e o corno uterino direitos posicionamse ventralmente ao cólon descendente, enquanto os mesmos esquerdos, dispóemse dorsalmente. Nos machos, averiguou-se que fazem o mesmo tipo de relação com os ureteres, porém também se observou os ductos paramesonéfricos ${ }^{14}$ fazendo relação semelhante às dos cornos uterinos.

Quando o cólon descendente adentra a CP mantém uma disposição retilínea em relação ao PM, porém passa a ser chamado de reto. Este não apresenta saculaçóes, tendo a aparência de um tubo liso com um ligeiro pregueamento, exceto por uma pequena região localizada mais caudalmente onde observamos uma leve dilatação, a ampola retal. Observou-se o reto com, em média, $3,8 \mathrm{~cm}$, entretanto em machos com cerca de $4,1 \mathrm{~cm}$, devido ao fato destes apresentarem a CP mais alongada que as fêmeas, pois os testículos ficam no interior da CA, quando fora de período reprodutivo. As fêmeas apresentaram em média um comprimento de $3,5 \mathrm{~cm}$, e sua CP foi observada apresentando um diâmetro transverso maior. Não foram encontrados dados comparativos relacionados à morfometria do reto entre machos e fêmeas.

Durante a análise dos espécimes observou-se que a gordura subperitoneal encontrava-se em pouca quantidade, principalmente nos animais mais jovens. Este fato implicou na evidenciação das pregas peritoniais sendo finas e, em alguns casos muito delgadas e de difícil visualização. Comparado aos gambás ${ }^{12}$, inferimos que há uma divergência, pois estes apresentam gordura subperitoneal ao longo da parede abdominal, não condizente aos resultados obtidos em nosso estudo.

Anexo ao AD temos a presença de glândulas que auxiliam na digestão e metabolização. Dentre estas se encontram as glândulas salivares parótida, mandibular e bucais ventral e lateral, as quais não apresentaram variaçóes nos aspectos relacionados à localizaçáo quando comparadas ao descrito para coelhos ${ }^{15}$. A glândula salivar parótida foi observada bem desenvolvida, com aproximadamente $1,3 \mathrm{~cm}$, com formato elipsóide irregular e posicionada lateralmente ao músculo masseter, desde a porção ventral da orelha externa até a região mandibular. Seu ducto salivar cursa lateralmente o músculo masseter e adentra a $\mathrm{CO}$ próximo ao diastema. $\mathrm{Na}$ regiāo ventral ao corpo da mandíbula evidenciou-se a presença da glândula salivar mandibular, cujo formato é ovóide e com tamanho aproximado de $0,8 \mathrm{~cm}$. Dorsalmente a esta última evidenciou-se a glândula salivar bucal 
ventral, a qual apresenta formato globoso e aproximadamente $0,3 \mathrm{~cm}$. A glândula salivar bucal lateral foi observada rostralmente e posicionada lateralmente ao músculo bucinador, apresentando formato, também, globoso e alongado, tendo tamanho médio de $1,0 \mathrm{~cm}$. Não constatamos a presença da glândula salivar zigomática, que se encontra presente em coelhos ${ }^{15}$. Apesar dos dados morfológicos e topográficos analisados, não se pode proceder à comparação morfométrica, devido ao fato de não terem sido encontrados relatos sobre este aspecto para estas glândulas dentre as espécies analisadas.

O fígado apresenta-se bem desenvolvido e divido em seis lobos, muito semelhante ao descrito para os carnívoros ${ }^{10}$. Sendo estes os lobos hepáticos mediais direito e esquerdo, lobos hepáticos laterais direito e esquerdo, lobos hepáticos quadrado e caudado. O lobo caudado apresenta o processo papilar, cranialmente e o processo caudato, caudalmente. Seu peso aproximado foi de $17,5 \mathrm{~g}$. Dispóe-se em grande parte à direita do plano mediano, ocupando desde o teto da CA até o assoalho desta, entre a nona e a $12^{a}$ costela. Sua face parietal está em contato com o diafragma. Encontra-se fixo pelos ligamentos falciforme (à porção esternal do músculo diafragma e assoalho da CA), redondo (à cicatriz umbilical), coronário (à Veia Cava Caudal), triangulares esquerdo e direito (fixando, respectivamente, os lobos laterais esquerdo e direito ao músculo diafragma), hepato-renal (ao rim direito) e omento menor (ao estômago e duodeno cranial). Quanto à fixação deste órgão foi evidenciado de forma similar ao coelho ${ }^{6}$. Contudo, o ligamento hepato-renal foi observado dirigido propriamente ao rim direito e não à parede abdominal como relatam os mesmos autores. A vesícula biliar encontra-se entre os lobos hepáticos medial direito e quadrado, assim como o evidenciado em gambás ${ }^{12}$. O ducto cístico desemboca no divertículo duodenal.

O pâncreas apresenta formato alongado e situa-se em maior concentração à direita do PM, entre o duodeno descendente e o duodeno ascendente, dorsalmente ao cólon transverso. Porém, dirige-se ao estômago, percorrendo sua curvatura maior. Apresenta-se pouco desenvolvido o que torna difícil sua visualização macroscópica. Seu peso em média foi de 1,5 g. Encontra-se, sobre o mesoduodeno, disposto nos terços dorsal e médio da CA. Seu ducto desemboca no divertículo duodenal.

$\mathrm{O}$ baço apesar de não fazer parte do AD é didaticamente descrito junto a este por apresentar íntima relação com o estômago, ao qual se situa dorso-lateralmente à esquerda, junto ao gradil costal, entre o $10^{\circ}$ e $11^{\circ}$ EIC. Apresenta formato irregular semelhante aos carnívoros, pesando aproximadamente 2,23 g. Fixa-se ao estômago pelo omento gastro-esplênico. Sua posição, dorso-caudal ao estômago, assemelha-se ao citado para gambás ${ }^{12}$. Porém não foi observada a orientação ventral em direção à cartilagem xifóide relatada pelos mesmos autores.

\section{Conclusão}

De posse dos resultados concluímos que apesar da chinchila ser um roedor, apresenta características próprias da espécie e também outras que se assemelham aos lagomorfos, constituindo uma relação entre essas ordens. Deste modo, constatamos que a CO apresenta a papila incisiva proeminente e os dentes são constituídos por quatro incisivos, em forma de pinça, distribuídos aos pares no osso incisivo e corpo da mandíbula, oito molariformes maxilares e oito mandibulares, totalizando dez dentes maxilares e dez mandibulares. O esôfago apresenta trajeto e disposição semelhantes ao descrito para outras espécies domésticas. Já o estômago foi observado como sendo monocavitário simples e disposto desde o teto até o assoalho da CA, 2/3 à esquerda do PM.

No intestino delgado averiguouse que o duodeno cranial apresenta o divertículo duodenal aproximadamente 1,0 $\mathrm{cm}$ após o piloro. $\mathrm{O}$ duodeno não apresentou 
variações na sua disposição. Quanto ao jejuno observou-se que se encontra fixo ao teto da CA, ligeiramente deslocado à direita do PM. Evidenciou-se no íleo variaçóes em sua disposição, com o seu trajeto da direita para esquerda.

O ceco apresenta-se bem desenvolvido, posicionado à esquerda do PM e divido em duas porçóes distintas, uma espiralsacular e outra como uma dupla alça paralela, apresentando pequenas saculaçóes subsequentes. O cólon ascendente dispóese em forma de uma dupla espiral, desde a entrada da CP até o nível da $12^{a}$ costela. No cólon transverso não foram evidenciadas alteraçóes posicionais. $\mathrm{O}$ cólon descendente apresenta-se bastante extenso, dispondo-se de forma ondulatória-irregular fixo ao teto da $\mathrm{CA}$, e concentrado à esquerda do PM, dorsal ao ceco. Os machos, em média, apresentaram o reto com maior comprimento quando comparados às fêmeas.

Em anexo ao $\mathrm{AD}$ observamos que a gordura subperitoneal encontrava-se em pouca quantidade nos espécimes estudados. As glândulas salivares parótida, mandibular e bucais ventral e lateral foram evidenciadas semelhantes ao descrito aos lagomorfos. $\mathrm{O}$ fígado foi observado bem desenvolvido e apresentando seis lobos, sendo dois destes os lobos hepáticos medial direito e quadrado, entre os quais se encontra a vesícula biliar. Em relação ao pâncreas, constatamos que este apresenta formato alongado e bastante delgado, estando disposto entre o duodeno descendente e duodeno ascendente, dirigido à curvatura maior do estômago, sobre o mesoduodeno. Já o baço, evidenciou-se com um formato irregular e com disposição semelhante ao descrito para outras espécies.

\title{
Morphological, morphometric and topographical description of the digestive tract in Chinchilla lanigera
}

\begin{abstract}
The aim of this study was to describe the morphological and topographic aspects of the chinchilla's digestive apparatus (DA) through dissection of ten animals. We collected the DA segments and made the volumetric analysis of cavitary organs through injection of saline solution at $60^{\circ} \mathrm{C}$, and measuring of the tubular organs. The parenchymal organs were weighed. During analysis of the position of organs, evisceration and measuring, it was observed that the oral cavity is typical of rodents, the salivary glands are similar to lagomorphs and organs as esophagus, stomach, duodenum, transversal colon, liver, pancreas and spleen were disposed in similar way to described to other species. On the other hand, jejunum and descending colon were found to be very long and disposed on a wavy way, hanging from the roof of the abdominal cavity. The ileum was found to be similar to other species, but its topographic disposition is from the right to the left, heading to cecum, which is made of two well developed distinct portions. Both portions are located to the left of the median plane. Ascending colon is disposed in a very particular way, in which we observe a double loop which makes a circle at the liver. A relevant characteristic was in evidence comparing the rectum of males and females: males' is longer. Based on these data we conclude that despite the fact that chinchillas are rodents, they have particular characteristics of their own, and other characteristics similar to lagomorphs, being then a connection between these orders.
\end{abstract}

\author{
Keywords: \\ Anatomy. \\ Digestive apparatus. \\ Topography. \\ Morphometry. \\ Chinchilla.
}




\section{Referências}

1 COOK, M. J. The anatomy of the laboratory mouse. London: Academic Press, 1965.

2 SNIPES, R. L. Anatomy of the cecum of the gerbil, Meriones unguiculatus (Mammalia, rodentia, cricetidae). Zoomorphology, v. 100, n. 3, p. 189-202, 1982.

3 HOLTENIUS, K.; BJORNHAG, G. The colonic separation mechanism in the guinea-pig (Cavia porcelus) and the chinchilla (Chinchilla laniger). Comparative Biochemestry and Physiology A-Physiology, v. 82, n. 3, p. 537-542, 1985 .

4 WANG, D. H.; PEI, Y. X.; YANG, J. C.; WANG, Z. W. Digestive tract morphology and food habits in six species of rodents. Folia Zoologica, v. 52, p. 51-55, 2003.

5 WEIJS, W. A.; DANTUMA, R. Functional-anatomy of the masticatory apparatus in the rabbit (Oryctolagus cuniculus). Netherlands Journal of Zoology, v. 31, n 1, p. 99-147, 1981.

6 PÉREZ, W.; MÖLLER, R.; MARTIN, E. Peritoneal folds of the rabbit (Oryctolagus cuniculus). Anatomia Histologia Embryologia Journal of Veterinary Medicine Series C, v. 34, n. 3, p. 167-170, 2005.

7 HILDEBRAND, M. Análise da estrutura dos vertebrados. São Paulo: Atheneu, 1995.

8 POPESKO, P. Atlas de anatomia topográfica dos animais domésticos. São Paulo: Manole, 1985. v. 1-3.

9 VAN ZYL, A.; RAMBAU, R. V.; VAN DER MERWE, M. Aspects of the anatomy and histology of the alimentary canal of the greater cane rat, Thryonomys swinderianus, with reference to its feeding physiology. African Zoology, v. 40, n. 1, p. 25-36, 2005.
10 DYCE, K. M.; SACK, W. O.; WENSING, C. J. G. Tratado de anatomia veterinária. 2. ed. Rio de Janeiro: Guanabara Koogan, 1997.

$11 \mathrm{KÖNIG}, \mathrm{H}$. E.; LIEBICH, H- J. Anatomia dos animais domésticos. Porto Alegre: Artmed, 2002. v. 2.

$12 \mathrm{KOCH}$, R.; GASSE, H.; WILKENS, H. Topographic anatomy of the abdominal organs of the gray shorttailed opossum, Monodelphis-domestica (Marsupialia). Zeitschrift für Versuchstierkude, v. 33, p. 251-258, 1990.

13 MÖLlER, R.; PÉREZ, W.; MARTIN, E. Divisiones del ciego y colon ascendente del conejo (Oryctolagus cuniculus). Veterinaria (Montevideo), v. 37, p. 23-26, 2002.

14 MOORE, K. L.; PERSAUD, T. U. N. Embriologia clínica. 6. ed. Rio de Janeiro: Guanabara Koogan, 2002. p. 313.

15 HAKIM, S. G.; LAUER, I.; KOSMEHL, H.; SIEG, $P$. The superficial mandibular gland of the rabbit: a new experimental model for scintigraphic evaluation of salivary glands. International Journal of Oral \& Maxillofacial Surgery, v. 31, p. 303-308, 2002.

16 BARONE, R. Anatomie compare des mammiféres dosmestiques. Splanchnologie I. Appareil digestif, appariel respiratoire. 3rd edn. Paris: Vigot Fréres, 1997. v. 3

17 BARONE, R. Anatomie compare des mammiféres dosmestiques. Splanchnologie II. Appareil uro-génital, foetus et ses annexes, péritoine et topographie abdominale. 3rd edn. Paris: Vigot Fréres, 2001, v. 4.

18 INTERNATIONAL COMMITTEE ON VETERINARY GROSS ANATOMICAL NOMENCLATURE, Nomina anatomica veterinaria. 4. ed. Ithaca: Dep. Vet. Anat., Cornell University, 1994.

19 SCHWARZE, E.; SCHRÖDER, L. Compendio de anatomia veterinaria. Zaragoza: Acribia, 1970. Tomo II. 